\title{
Sistem Pendukung Keputusan Teknisi Terbaik PT.Telkom Indonesia Tanjungpinang Menggunakan Metode TOPSIS
}

\author{
Mohammad Rizki Romdoni ${ }^{1}$, Muhammad Faizal ${ }^{2}$, Gunawan Pratama ${ }^{3}$ \\ ${ }^{1,2,3}$ Jurusan Sistem Informasi STT Indonesia Tanjungpinang \\ Jln. Pompa Air No. 28 Tanjungpinang Kepulauan Riau Indonesia \\ 1'mr.romdoni@gmail.com \\ 2 faizalstti@gmail.com \\ 33beningutami123@gmail.com
}

\begin{abstract}
Intisari- Informasi sangat dibutuhkan dalam proses pengambilan keputusan. Keputusan yang baik dan tepat perlu didukung oleh ketersediaan informasi yang akurat, cepat dan relevan. Dengan informasi yang demikian, kepala kantor atau pimpinan suatu lembaga atau organisasi dapat gambaran yang komplek dan spesifik dari suatu keputusan yang akan dirumuskan. Keputusan akan efisien dari aspek waktu karena data dapat diakses secara instan. Di samping itu keakuratan data lebih terjamin, sehingga keputusan yang dirumuskan akan lebih tepat dan dapat dirumuskan dalam waktu yang relatif lebih singkat. Selama ini PT.Telkom Indonesia Tanjungpinang dalam pengambilan keputusan untuk memilih teknisi terbaik tidak berdasarkan data yang kualitatif yang membandingkan setiap kriteria yang ada, sehingga penilaian hanya dilakukan oleh kepala kantor maupun asman dengan memilih teknisi yang menurutnya terbaik tanpa mempertimbangkan kriteria-kriteria yang diperlukan. Jadi penilaian yang dilakukan hanya berdasarkan hasil voting suara dan juga perhitungan yang dilakukan juga tidak komputerisasi sehingga data yang lama sering sekali hilang dari pembukuan. Dengan adanya Sistem Pendukung Keputusan Teknisi Terbaik Berbasis Web bisa membantu Kepala Kantor dalam menangani permasalahan diatas, sistem ini dibuat menggunakan metode TOPSIS (Technique For Others Reference by Similarity to Ideal Solution) dengan bahasa pemrograman PHP dan Mysql sebagai databasenya, serta metode permodelan perangkat lunak menggunakan UML.

Kata kunci : Sistem, SPK, TOPSIS, PT.Telkom Indonesia Tanjungpinang
\end{abstract}

\begin{abstract}
Information is needed in the decision making process. Good and right decisions need to be supported by the availability of accurate, fast and relevant information. With such information, the head of an office or head of an institution or organization can get a complex and specific picture of a decision to be formulated. The decision will be efficient in terms of time because the data can be accessed instantly. In addition, the accuracy of the data is more guaranteed, so that decisions that are formulated will be more precise and can be formulated in a relatively short time. So far, PT Telkom Indonesia Tanjungpinang in making the decision to choose the best technician is not based on qualitative data comparing each existing criterion, so that the assessment is only carried out by the head of the office or asman by selecting the technician who he thinks is the best without considering the required criteria. So the assessment is only based on the results of voting votes and also the calculations carried out are also not computerized, so that old data is often lost from the books. With the Web-Based Best Technician Decision Support System to help the Head of the Office in dealing with the above problems, this system was created using the TOPSIS (Technique For Others Reference by Similarity to Ideal Solution) method with the PHP and Mysql programming languages as the database, as well as the software modeling method using UML.
\end{abstract}

Keywords: System, SPK, TOPSIS, PT Telkom Indonesia Tanjungpinang

\section{PENDAHULUAN}

Perkembangan teknologi yang sangat maju di era modern dan globalisasi memungkinkan berbagai kegiatan dilakukan secara efektif dan efisien. Dimana perkembangan teknologi ini tidak hanya memberi pengaruh dalam pengolahan data suatu perusahaan atau instansi formal maupun nonformal, juga berpengaruh cara kerja manusia dalam pengambilan keputusan, salah satunya untuk menentukan teknisi terbaik juga membutuhkan sistem yang efektif dan efisien dalam menentukan keputusan teknisi yang terbaik sesuai dengan yang diharapkan, untuk itu diperlukan suatu Sistem Pendukung Keputusan (SPK). ${ }^{[1]}$

Informasi sangat dibutuhkan dalam proses pengambilan keputusan. Keputusan yang baik dan tepat perlu didukung oleh ketersediaan informasi yang akurat, cepat dan relevan. Dengan informasi yang demikian, supervisor/pimpinan suatu lembaga/organisasi dapat gambaran yang komplek dan spesifik dari suatu keputusan yang akan dirumuskan. Keputusan akan efisien dari aspek waktu karena data dapat diakses secara instan. Di samping itu keakuratan data lebih terjamin, sehingga keputusan yang dirumuskan akan lebih tepat dan dapat dirumuskan dalam waktu yang relatif lebih singkat.

Dalam pengambilan keputusan ini, dibutuhkannya suatu sistem pengambilan keputusan yang dapat membantu seorang pimpinan untuk mengambil keputusan. Istilah Sistem Pendukung Keputusan (SPK) atau lebih dikenal dengan Decision Support System (DSS) merupakan suatu sistem untuk mendukung para pengambil keputusan manajerial dalam situasi keputusan semi 
terstruktur. Sistem ini dimaksudkan untuk menjadi alat bantu bagi para pengambil keputusan untuk memperluas kapabilitas mereka, namun tidak untuk menggantikan penilaian mereka.

PT. Telkom Indonesia adalah perusahaan informasi dan komunikasi serta penyedia jasa dan jaringan telekomunikasi secara lengkap di Indonesia. Telkom mengklaim sebagai perusahaan telekomunikasi terbesar di Indonesia. Telkom merupakan salah satu BUMN yang $52,09 \%$ sahamnya saat ini dimiliki oleh Pemerintah Indonesia, dan 47,91\% dimiliki oleh publik, Bank of New York, dan investor dalam negeri. Telkom juga menjadi pemegang saham mayoritas di 13 anak perusahaan, seperti PT Telekomunikasi Seluler (Telkomsel), Telkom Akses.

Teknisi Telkom Akses adalah orang yang bertugas di bidang konstruksi pembangunan dan manage service infrastruktur jaringan, menguasai jaringan PT.Telkom Indonesia untuk memberikan pelayanan ke pelanggan PT. Telkom Indonesia. Teknisi terbaik adalah teknisi yang memiliki kinerja dan kompetensi, kepribadian dan profesional hingga disiplin kerja yang melampaui standar.

PT.Telkom Akses Tanjungpinang dalam pengambilan keputusan untuk memilih teknisi terbaik tidak berdasarkan data yang kualitatif yang membandingkan setiap kriteria yang ada, sehingga penilaian hanya dilakukan oleh pelanggan maupun pegawai PT.Telkom Indonesia dengan memilih teknisi yang menurutnya terbaik tanpa mempertimbangkan kriteria-kriteria yang diperlukan. Jadi penilaian yang dilakukan hanya berdasarkan hasil voting suara dan juga perhitungan yang dilakukan juga tidak komputerisasi sehingga data yang lama sering sekali hilang dari pembukuan. Dalam hal ini sangat diperlukan sistem yang dapat menggabungkan antara pendukung keputusan dan komputerisasi dengan menggunakan perhitungan yang tepat, untuk membantu menilai setiap teknisi berdasarkan kriteria atau faktor yang dijadikan pertimbangan, sehingga hasil yang didapat lebih objektif.

Metode Technique For Others Reference by Similarity to Ideal Solution (TOPSIS) merupakan metode yang cocok digunakan dalam penilaian untuk menentukan teknisi terbaik karena metode ini memiliki konsep yang sederhana, mudah dipahami, komputerisasinya efisien dan memiliki kemampuan untuk mengukur kinerja relatif dari alternatif-alternatif keputusan dalam bentuk matematis yang sederhana. Dari uraian diatas penulis bermaksud untuk membuat sebuah sistem pendukung keputusan yang bisa membantu kinerja dalam membantu pengambilan suatu keputusan teknisi terbaik dengan menggunakan metode Technique For Others Reference by Similarity to Ideal Solution (TOPSIS).

\section{METODOLOGI PENELITIAN}

\section{A. Sistem Pendukung Keputusan}

Pada awalnya Turban \& Aronson (1998) mendefinisikan sistem penunjang keputusan (Decision Support Systems - DSS) sebagai sistem yang digunakan untuk mendukung dan membantu pihak manajemen melakukan pengambilan keputusan pada kondisi semi terstruktur dan tidak terstruktur. Pada dasarnya konsep DSS hanyalah sebatas pada kegiatan membantu para manajer melakukan penilaian serta menggantikan posisi dan peran manajer. ${ }^{[2]}$

Konsep DSS pertama kali diperkenalkan pada awal tahun 1970-an oleh Michael Scott Morton, yang selanjutnya dikenal dengan istilah "Management Decision System". Konsep DSS merupakan sebuah sistem interaktif berbasis komputer yang membantu pembuatan keputusan memanfaatkan data dan model untuk menyelesaikan masalah-masalah yang bersifat tidak terstruktur dan semi terstruktur. DSS dirancang untuk menunjang seluruh tahapan pembuatan keputusan, yang dimulai dari tahapan mengidentifikasi masalah, memilih data yang relevan, menentukan pendekatan yang digunakan dalam proses pembuatan keputusan sampai pada kegiatan mengevaluasi pemilihan alternatif.

\section{METODOLOGI PENELITIAN}

\section{A. Pengumpulan Data}

Dalam kegiatan untuk memperoleh data pada penelitian Skripsi ini, penulis menggunakan teknik pengumpulan data sebagai berikut:

\section{1) Observasi}

Metode pengumpulan data ini dilakukan dengan cara melakukan penelitian langsung pada objek yang bersangkutan yaitu PT. Telkom Indonesia.

2) Wawancara

Melakukan wawancara kepada piak yang bersangkutan sebagai tambahan informasi untuk pengembangan sistem yang dirancang.

3) Studi Pustaka

Mencari Informasi lain yang berasal dari buku-buku yang mendukung terhadap permasalahanpermasalahan yang diangkat, yaitu dengan mengumpulkan data-data dan teori-teori yang berhubungan dengan penulisan skripsi.

B. Pengembangan Perangkat Lunak

Metode pengembangan perangkat lunak ini menggunakan model Waterfall (Classic Life Cycle) yang menyarankan pengembangan perangkat lunak secara sistematik dan berurutan yang dimulai dari tingkatan sistem tertinggi dan berlanjut ke tahap analisis kebutuhan, desain sistem, penulisan kode 
program, pengujian dan penerapan program/pemeliharaan. Kelebihan dari metode ini adalah terstruktur, dinamis, dan sequential. ${ }^{[3]}$

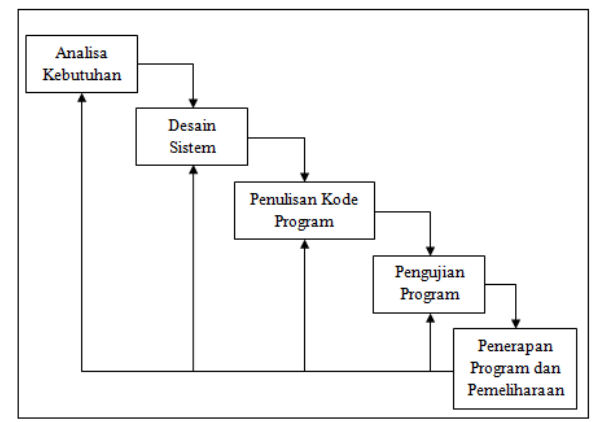

Gambar 1 Diagram Waterfall

Paradigma dari tahapan model waterfall adalah sebagai berikut : [4]

1) Analisa kebutuhan, langkah ini merupakan analisis terhadap kebutuhan sistem. Pengumpulan data dalam tahap ini bisa merupakan sebuah penelitian, wawancara, atau studi literature. Seorang sistem analisis akan menggali informasi sebanyak-banyaknya dari user sehingga akan tercipta sebuah sistem komputer yang bisa melakukan tugas-tugas yang diinginkan oleh user tersebut. Tahapan ini akan menghasilkan dokumen user requirement atau bisa dikatakan sebagai data yang berhubungan dengan keinginan user dalam pembentukan sistem. Dokumen inilah yang akan menjadi acuan sistem analisis untuk menerjemahkan ke dalam bahasa pemograman.

2) Desain Sistem, proses desain akan menerjemahkan syarat kebutuhan ke sebuah perancangan perangkat lunak yang dapat diperkirakan sebelum dibuat coding. Proses ini berfokus pada struktur data, arsitektur perangkat lunak, representasi interface, dan detail prosedural. Tahapan ini akan menghasilkan dokumen yang disebut software requirement. Dokumen inilah yang akan digunakan programmer untuk melakukan aktivitas pembuatan sistemnya.

3) Penulisan Kode Program, coding merupakan penerjemahan desain dalam bahasa yang dikenali oleh komputer. Dilakukan oleh programmer yang akan menerjemahkan transaksi yang diminta oleh user. Tahapan inilah yang merupakan tahapan secara nyata dalam mengerjakan suatu sistem. Dalam artian penggunaan komputer akan dimaksimalkan dalam tahapan ini.

4) Pegujian Program, tahap ini dilakukan setelah pengkodean selesai. Tujuan dilakukannya pengujian program adalah agar menetukan kesalahan-kesalahan terhadap sistem tersebut dan kemudian bisa diperbaiki.

5) Penerapan Program, tahap ini bisa dikatakan final dalam pembuatan sebuah sistem. Setelah melakukan analisi, desain, dan pengkodean maka sistem yang sudah jadi akan digunakan oleh user.

\section{HASIL DAN PEMBAHASAN}

A. Use case Diagram

Skenario use case untuk aplikasi Sistem Pendukung Keputusan menentukan teknisi terbaik dengan menggunakan metode TOPSIS adalah sebagai berikut :

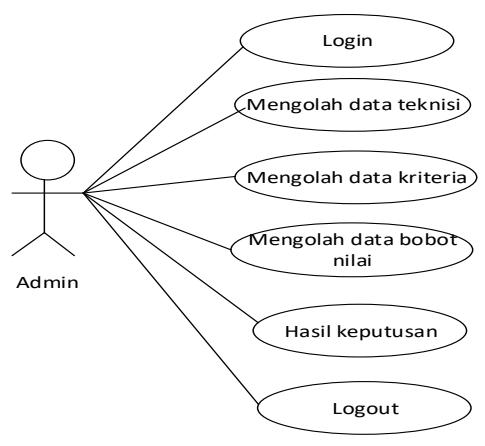

Gambar 2 Use case diagram ${ }^{[6]}$

Table 1 Use case

\begin{tabular}{|l|l|}
\hline $\begin{array}{l}\text { Use Case } \\
\text { Name }\end{array}$ & Login \\
\hline Summary & Proses untuk masuk ke sistem \\
\hline Actor & Admin \\
\hline $\begin{array}{l}\text { Use Case } \\
\text { Name }\end{array}$ & Mengolah data teknisi \\
\hline Summary & $\begin{array}{l}\text { Proses input form data teknisi untuk } \\
\text { menambahkan data tenisi. }\end{array}$ \\
\hline Actor & Admin \\
\hline $\begin{array}{l}\text { Use Case } \\
\text { Name }\end{array}$ & Mengolah data kriteria \\
\hline $\begin{array}{l}\text { Summary } \\
\text { Actor }\end{array}$ & $\begin{array}{l}\text { Proses input form data kriteria untuk } \\
\text { menambahkan data kriteria }\end{array}$ \\
\hline $\begin{array}{l}\text { Ase Case } \\
\text { Name }\end{array}$ & Pengolahan data bobot nilai \\
\hline Summary & $\begin{array}{l}\text { Proses input data bobot nilai untuk } \\
\text { menambahkan data bobot nilai setiap } \\
\text { teknisi }\end{array}$ \\
\hline $\begin{array}{l}\text { Actor } \\
\text { Name Case }\end{array}$ & Admin \\
\hline $\begin{array}{l}\text { Summary } \\
\text { Actor }\end{array}$ & $\begin{array}{l}\text { Proses untuk mengetahui hasil dari } \\
\text { keputusan teknisi terbaik }\end{array}$ \\
\hline Admin \\
\hline
\end{tabular}


Bangkit Indonesia, Vol. VII, No. 02, Bulan Oktober 2018

\begin{tabular}{|l|l|}
\hline $\begin{array}{l}\text { Use Case } \\
\text { Name }\end{array}$ & Logout \\
\hline Summary & Proses untuk keluar dari sistem \\
\hline Actor & Admin \\
\hline
\end{tabular}

B. Activity Diagram

1). Activity Diagram Login

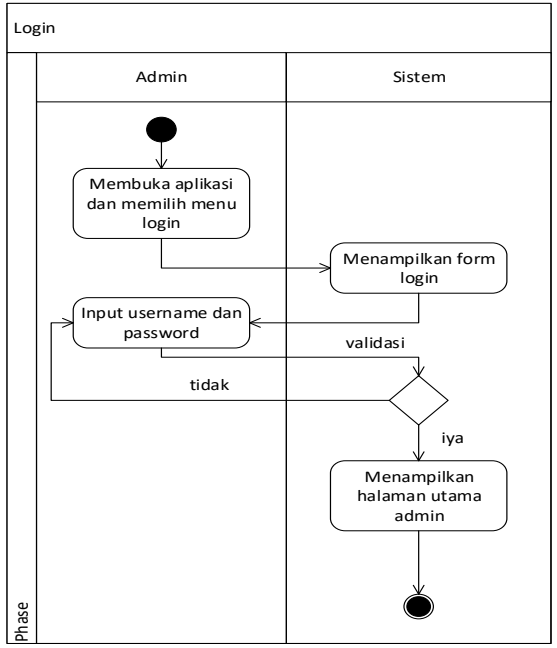

Gambar 3 Activity Diagram

$\operatorname{Login}^{[7]}$

\section{2). Activity Diagram Data Teknisi}

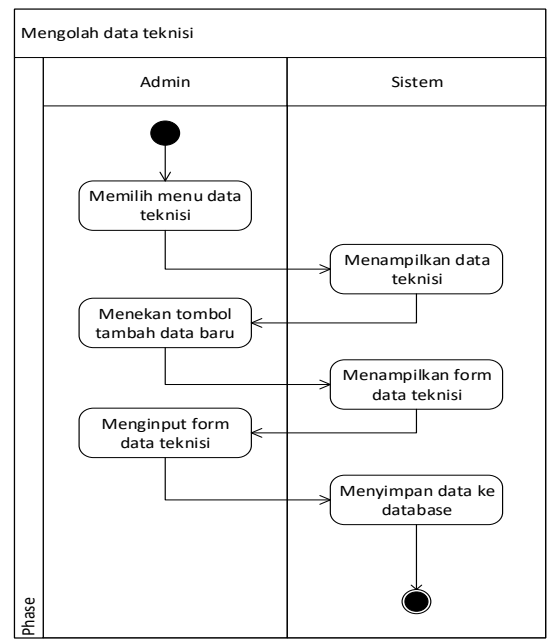

Gambar 4 Activity Diagram Mengolah data teknisi ${ }^{[8]}$

3) Activity Diagram Data Kriteria

6) Activity Diagram Logout 


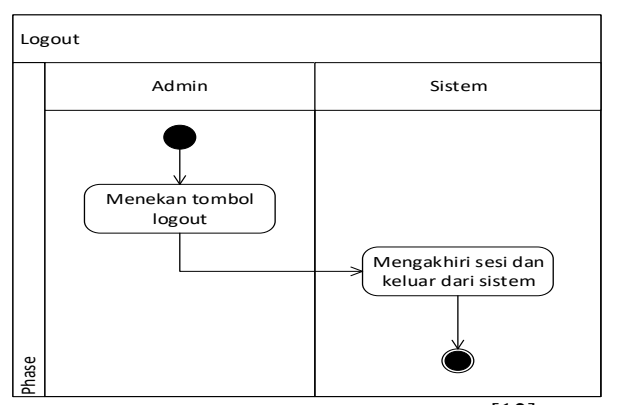

Gambar 8 Activity diagram logout ${ }^{[12]}$

\section{KESIMPULAN DAN SARAN}

Kesimpulan merupakan ringkasan yang diambil dari pembahasan terhadap rancangan perangkat lunak. Beserta saran yang dikumpulkan dari hasil pengujian penggunaan dari pada perangkat lunak yang dirancang sebagai bahan pertimbangan dalam upaya peningkatan daya kerja di PT.Telkom Indonesia Tanjungpinang agar menjadi lebih baik. Berdasarkan hasil proses perancangan dan pembuatan perangkat lunak yang dibuat untuk PT.Telkom Indonesia Tanjungpinang, penulis menyimpulkan bahwa :

1. Proses pemilihan teknisi terbaik sudah menjadi lebih efektif dengan adanya Sistem Pendukung Keputusan Teknisi Terbaik dengan Metode TOPSIS karna proses penilaian dihitung berdasarkan kriteria-kriteria yang dijadikan pertimbangan.

2. Proses pembuatan laporan menjadi lebih mudah dan menghemat waktu dan ruangan penyimpanan karna proses dilakukan secara terkomputerisasi.

3. Proses pencarian data dan informasi lebih cepat dan akurat karna data disimpan dalam sebuah database yang dapat dicari sewaktu-waktu tanpa memakan waktu yang banyak.

Dari hasil pengamatan penulis dengan melakukan penelitian, perancangan hingga membuat pembuatan perangkat lunak untuk sistem pendukung keputusan teknisi terbaik berbasis web, penulis mendapatkan beberapa saran diantaranya :

a. Disarankan agar dapat melakukan pemeliharaan sistem secara berkala.

b. Pengembangan sistem pendukung keputusan ini agar kiranya dapat disingkronasikan dengan sistem yang sudah ada pada PT.Telkom Indonesia Tanjungpinang

c. Fitur yang dapat ditambahkan pada aplikasi ini selanjutnya yaitu seperti voting dari pelanggan PT.Telkom Indonesia.

\section{REFERENSI}

[1] Alan Nur Aditya, Jago PHP \& MySQL, [Bekasi - Jawa Barat:DUNIA KOMPUTER, 2011]

[2] Andrea Adelheid, Cara mudah Bikin Website \& Promosi Ke Seo [Yogyakarta:Mediakom, 2015]

[3] Andi,,Pemrograman PHP dan My SQL Untuk Pemula, [Yogyakarta:MADCOMS, 2016]

[4] Dri Atmaka, Tpis Menjadi Guru Kreatif, 2004

[5] Duwi Priyatno, Panduan Lengkap Komputer: PC, Laptop, Tablet [Depok, Media Pusindo, 2012]

[6] Hermawan, Julius, Membangun Decision Support System, [Yogyakarta: Andi, 2005]

[7] Muhammad Dimas T.S., Pembuatan Aplikasi Game Dark Side of the Moon [Bandung, Universitas Widyatama, 2015]

[8] Nur Dwi Sartika, Sistem Informasi Pengiriman Barang Berbasis WEB Dengan Metode Transshipment, [2014]

[9] Pratama Gunawan, Aplikasi Database Keluar Masuk Modem PT.Telkom Akses Tanjungpinang, [Tanjungpinang:STTI, 2018]

[10] Prabowo podjo widodo herlawati, ,Menggunakan UML, [Bandung: Informatika, 2011]

[11] Surbakti, Irfan, Sistem Pendukung Keputusan (Decision Support System), [Yogyakarta : Graha Ilmu, 2002]

[12] Tohari Hanif, Anlisis Serta Perancangan Sistem Informasi Melalui Pendekan UML [Andi, 2014, Yogyakarta] 